\title{
Histogramas de parição e o desempenho reprodutivo de vacas de corte
}

\author{
Calving histograms and reproductive performance of the beef cows \\ Cristiane Reinher ${ }^{1}$, Ricardo Pedroso Oaigen², Júlio Otávio Jardim Barcellos ${ }^{3}$, \\ Alexandre Meyer ${ }^{2}$, Ënio Rosa Prates ${ }^{3}$, José Braccini Neto $^{3} \&$ Jaime Cobucci ${ }^{3}$
}

\begin{abstract}
RESUMO
A distribuição dos partos em vacas de corte, durante a estação de parição, está relacionada com o desempenho reprodutivo final do rebanho de cria, sendo um dos principais fatores a influenciar na rentabilidade do sistema de produção no sul do Brasil. O objetivo do presente trabalho foi avaliar o efeito do histograma de parição (HP) sobre a taxa de prenhez (TP) de 1.314 vacas de corte primíparas e 4.519 multíparas Hereford e cruzas Hereford-Nelore, no período de 1997 a 2004, numa criação comercial, utilizando o programa estatístico SPSS. Houve efeito significativo $(\mathrm{P}<0,05)$ entre anos em relação à TP. Os HP no rebanho avaliado estão distantes do modelo ideal. A ocorrência de limitações climáticas no acasalamento diminuiu a taxa de prenhez, contudo o efeito foi de menor magnitude quando o HP de parição foi mais concentrado nos primeiros 42 dias. As vacas primíparas apresentaram histogramas com grande concentração de partos no início da estação. Deste modo foram menos sensíveis às adversidades climáticas do que as multíparas. Portanto, o histograma de parição tem um efeito na taxa de prenhez subseqüente, especialmente nas situações onde ocorrem limitações nutricionais no pós-parto ou durante o acasalamento.
\end{abstract}

Descritores: vacas de cria, primíparas, multíparas, parição, taxa de prenhez.

\section{ABSTRACT}

The calving distribution of the beef cow during the season was related to the reproductive performance of the cow-calf operation, since it the major factor that determine the production system profitability at the Southern of Brazil. This work was conducted to evaluate the calving histogram $(\mathrm{CH})$ effect on the pregnancy rate (PR) of the 1,314 primiparous and 4,519 multiparous Hereford and Hereford-Nelore cows during eight years (1997-2004), in commercial livestock. The PR were influenced by years and their histogram $(\mathrm{P}<0.05)$. The cows showed a different $\mathrm{CH}$ than the theoretical model. The climate limitations during the mating season affected the PR, however the effect were of the lower when the $\mathrm{CH}$ were concentrate in the first 42 days interval. The primiparous cows showed the $\mathrm{CH}$ with higher concentration in the beginning the season calving. Therefore, the effect of the climate on the PR was lower in primiparous. In this case the PR were affected by the $\mathrm{CH}$, mainly in years where the nutritional restriction in the pos-partum or mating season occurred.

Key words: cow-calf, multiparous, primiparous, calving, pregnancy rate. 


\section{INTRODUÇÃO}

A eficiência reprodutiva de um rebanho de cria é consequiência de uma série de variáveis inter-relacionadas, que vão desde fatores intrínsecos ao animal até condições ambientais específicas. Nos sistemas de produção mais intensivos a estação de parição é seguida de uma temporada de acasalamento de mesma duração, com início e fins previamente estabelecidos [2,4]. A utilização da estação de acasalamento permite o estabelecimento de um período de parição ajustado às condições nutricionais, climáticas, sanitárias e de mercado [7], resultando na formação de lotes de produtos homogêneos ao desmame [1].

Em sistemas de produção baseados nas pastagens naturais, vacas que concebem ao final da estação de acasalamento serão as últimas a parir dentro da estação de parição seguinte. Como conseqüência, estas fêmeas podem iniciar a estação reprodutiva em fase puerperal ou em anestro [10]. Por outro lado, dentro de uma estação de parição com duração limitada, a fêmea que pare ao início deste período, apresenta um maior tempo de recuperação do puerpério no pósparto, resultando um maior número de cios e maior probabilidade de prenhez [8].

A forma de expressar a frequiência dos partos na estação de parição se dá por meio do histograma, construído pelo percentual de vacas que parem a cada intervalo de 21 dias e, cuja distribuição teórica ideal é em torno de $60 \%$ dos partos nos primeiros 21 dias da estação [1]. Portanto, é viável acreditar que pelo tipo de histograma de parição possa ocorrer uma estimativa da provável prenhez futura. Neste sentido, foi realizado o presente trabalho para avaliar o efeito da distribuição da parição sobre a taxa de prenhez de vacas de corte.

\section{MATERIAIS E MÉTODOS}

O trabalho foi realizado a partir dos registros de uma criação comercial de bovinos de corte, situada na região da campanha do Estado do Rio Grande do Sul, especializada na produção de bezerros. Foram analisados dados de 1.314 vacas de corte primíparas, aos 36/37 meses de idade e 4.519 vacas de corte multíparas entre quatro e dez anos da raça Hereford e cruzas Hereford-Nelore, durante os anos de 1997 a 2004.

O clima da região é subtropical, com chuvas regularmente distribuídas no ano, e ocasionalmente períodos de seca de dezembro a janeiro. A vegetação predominante é a grama-forquilha (Paspalum notatum) e uma pequena incidência de trevos nativos. A disponibilidade de matéria seca (MS) no período pré-parto varia de 700 a $1200 \mathrm{~kg} /$ hectare e no pós-parto de 1000 a $1600 \mathrm{~kg}$ de MS. Portanto, o manejo alimentar é semelhante entre primíparas e multíparas, sendo mantidas apenas em lotes separados. As novilhas são acasaladas aos dois anos de idade no período de 15 de novembro a 15 de janeiro, e o primeiro parto ocorre de 24 de agosto a 25 de outubro, portanto, num período de sessenta dias. As multíparas são acasaladas de 15 de novembro a 15 de fevereiro, com duração de 90 dias, ocorrendo os partos durante o período de 24 de agosto a 25 de novembro. Todas as vacas durante a estação de acasalamento, estão com seus bezerros, pois o desmame é realizado somente após o término deste período.

O histograma de partos (HP) foi elaborado a partir de registros coletados a campo, onde um parteiro anota o número de nascimentos diários em cada categoria de vacas durante o período de parição. Após, esses dados foram processados, e calculada a frequiência dos partos em intervalos de 21 dias $(21,42,63,84)$.

O diagnóstico de gestação foi realizado por palpação retal aproximadamente 60 dias do término da estação de acasalamento. Portanto, a taxa de prenhez deste trabalho refere-se aos partos que ocorreram na estação de parição imediatamente anterior (invernoprimavera) ao diagnóstico de gestação.

Os dados foram analisados considerando o ano da parição (AP), o histograma de parição (HP) e categoria de vacas (primíparas e multíparas), e os seus possíveis efeitos na taxa de prenhez das vacas, pelo uso do qui-quadrado [9].

\section{RESULTADOS}

As Tabelas 1 e 2 apresentam as freqüências dos partos (HP) e a taxa de prenhez (TP) de vacas primíparas e multíparas nos diferentes anos e a média ponderada geral das taxas de prenhez no período analisado.

A análise estatística, para ambas as categorias de vacas demonstrou efeito significativo $(\mathrm{P}<0,05)$ dos anos em relação à taxa de prenhez. Estas diferenças não apresentaram uma relação direta com a distribuição dos partos durante a estação, pois os histogramas entre alguns anos não foram semelhantes. Esta diferença pode ser atribuída, em parte, às variações climáticas ocorridas durante a estação de acasalamento e suas consequiências sobre a disponibilidade dos pastos. 
Tabela 1. Distribuição da parição e a taxa de prenhez (TP) de vacas primíparas conforme o ano.

\begin{tabular}{|c|c|c|c|c|c|c|c|}
\hline \multirow{2}{*}{$\begin{array}{c}\text { Ano da } \\
\text { parição (AP) }\end{array}$} & \multicolumn{6}{|c|}{ Histograma de parição (\%) } & \multirow{2}{*}{$\operatorname{TP}^{\star \star}(\%)^{*}$} \\
\hline & 21d & $42 d$ & $63 d$ & $84 d$ & $1-42 d$ & 43-84d & \\
\hline 1997 & 17 & 56 & 21 & 6 & 73 & 27 & 85,6 a \\
\hline 1998 & 36 & 41 & 22 & 1 & 77 & 23 & $64,5 \mathrm{~b}$ \\
\hline 1999 & 31 & 63 & 6 & 0 & 94 & 6 & $94,5 \mathrm{c}$ \\
\hline 2000 & 27 & 46 & 17 & 10 & 73 & 27 & $96,5 \mathrm{c}$ \\
\hline 2001 & 35 & 52 & 12 & 2 & 87 & 13 & 86,9 a \\
\hline 2002 & 39 & 27 & 26 & 8 & 66 & 34 & $87,0 \mathrm{a}$ \\
\hline 2003 & 64 & 20 & 15 & 1 & 84 & 16 & $76,4 d$ \\
\hline 2004 & 30 & 25 & 28 & 17 & 55 & 45 & $64,7 \mathrm{~b}$ \\
\hline Média & 35 & 41 & 18 & 6 & 76 & 24 & 83,0 \\
\hline
\end{tabular}

"Médias na mesma coluna, seguidas de letras diferentes, diferem estatisticamente $(\mathrm{p}<0,05)$ pelo teste do Qui-Quadrado. ${ }^{* *} \mathrm{~A}$ taxa de prenhez refere-se ao diagnóstico de gestação no outono subseqüente. Portanto, para AP= 1997 a TP= obtida em abril 1998 e assim sucessivamente.

Tabela 2. Distribuição da parição e a taxa de prenhez (TP) de vacas multíparas conforme o ano.

\begin{tabular}{|c|c|c|c|c|c|c|c|}
\hline \multirow{2}{*}{$\begin{array}{c}\text { Ano da } \\
\text { parição (AP) }\end{array}$} & \multicolumn{6}{|c|}{ Histograma de parição (\%) } & \multirow{2}{*}{$\mathrm{TP}^{\star \star}(\%)^{\star}$} \\
\hline & 21d & $42 d$ & $63 d$ & $84 d$ & $1-42 d$ & $43-84 d$ & \\
\hline 1997 & 22 & 23 & 42 & 14 & 45 & 55 & 86,0 a \\
\hline 1998 & 2 & 29 & 40 & 29 & 31 & 69 & $53,5 \mathrm{~b}$ \\
\hline 1999 & 9 & 45 & 29 & 18 & 53 & 47 & $95,9 \mathrm{c}$ \\
\hline 2000 & 10 & 28 & 32 & 30 & 38 & 62 & $93,9 \mathrm{c}$ \\
\hline 2001 & 7 & 32 & 37 & 24 & 39 & 61 & 89,7 a \\
\hline 2002 & 20 & 34 & 27 & 19 & 54 & 46 & $81,1 d$ \\
\hline 2003 & 5 & 21 & 35 & 39 & 26 & 74 & $84,3 \mathrm{ad}$ \\
\hline 2004 & 13 & 23 & 30 & 34 & 36 & 64 & $67,5 \mathrm{e}$ \\
\hline Média & 11 & 29 & 34 & 26 & 40 & 60 & 80,6 \\
\hline
\end{tabular}

Em relação as primíparas (Tabela 1), não foram observadas diferenças na TP entre os anos de 1997 $(85,6 \%), 2001(86,9 \%)$ e $2002(87,0 \%) ; 1998(64,5 \%)$ e $2004(64,7 \%) ; 1999(94,5 \%)$ e $2000(96,5 \%)$. As taxas de repetição de prenhez dos anos 1998 e 2004 diferiu de todos os outros anos $(\mathrm{P}<0,05)$. Os resultados observados nas multíparas (Tabela 2) mostram que não foram observadas diferenças na TP do ano 1997 (86,0\%) em relação a 2001 (89,7\%) e 2003 (84,3\%) $(\mathrm{P}<0,05)$. Semelhante ao que ocorreu com as primíparas os dois piores índices de prenhez foram observados em $1998(53,5 \%)$ e $2004(67,5 \%)(\mathrm{P}<0.05)$. Os anos de 1998 e 2004 tiveram os piores índices de repetição de prenhez, $64,5 \%$ e $64,7 \%, 53,5 \%$ e $67,5 \%$, respectivamente para primíparas e multíparas.

As precipitações pluviométricas durante as estações de acasalamento encontram-se na Tabela 3. Nos períodos de 1998/99 (389 mm) e 2004/05 (200 mm) ocorreram as menores precipitações acumuladas quando comparadas com a média geral dos períodos avaliados $(580 \mathrm{~mm})$ e com a média histórica dos últimos 30 anos na região do experimento. Isto pode ter sido uma das causas a influenciar a TP das temporadas de parição 1998 e 2004 que tem um efeito associativo com o HP. 
Tabela 3. Precipitação pluviométrica durante a estação de acasalamento entre os anos de 1997 a 2004.

\begin{tabular}{cccccc}
\hline $\begin{array}{c}\text { Estação de } \\
\text { acasalamento } \\
\text { Anos-Meses }\end{array}$ & \multicolumn{5}{c}{ Precipitação pluviométrica (mm) } \\
\cline { 2 - 6 } & Novembro & Dezembro & Janeiro & Fevereiro & Acumulada \\
\hline $1997 / 1998$ & 130 & 340 & 228 & 311 & 1009 \\
$1998 / 1999$ & 124 & 137 & 48 & 80 & 389 \\
$1999 / 2000$ & 0 & 64 & 245 & 221 & 530 \\
$2000 / 2001$ & 138 & 103 & 180 & 74 & 495 \\
$2001 / 2002$ & 126 & 46 & 270 & 126 & 568 \\
$2002 / 2003$ & 248 & 451 & 85 & 185 & 969 \\
$2003 / 2004$ & 214 & 72 & 79 & 115 & 480 \\
$2004 / 2005$ & 134 & 36 & 20 & 10 & 200 \\
\hline Média & & & & & 580 \\
\hline
\end{tabular}

\section{DISCUSSÃO}

Os resultados apresentados nas Tabelas 1 e 2 demonstram claramente que a TP média no período analisado (8 anos) pode ser considerada alta comparada com médias regionais [5], o que evidencia que as variáveis ambientais e de manejo do sistema de produção são controladas.

O histograma de parição permite conhecer a distribuição dos partos do rebanho de cria e em alguns casos projetar, a provável taxa de prenhez ou determinar estratégias de manejo que minimizem os efeitos de um histograma desfavorável. Isto se baseia no princípio que, os nascimentos ocorrendo com maior freqüência nos primeiros 21 dias possibilita um maior período para recuperação das vacas e conseqüentemente melhor desempenho reprodutivo [8].

No presente experimento, pelas dificuldades de interpretar as comparações entre médias da TP rela- cionadas aos respectivos HP, optou-se por uma discussão geral e posteriormente centralizada naqueles anos em que foram observados menores valores para a TP.

A Figura 1 apresenta um modelo teórico de um histograma de parição ideal e os histogramas das vacas primíparas e multíparas, médio dos oito anos analisados. Observa-se que as primíparas se aproximam mais do modelo ideal, devido a menor duração de sua primeira estação reprodutiva quando novilhas, tendo como conseqüência uma parição mais concentrada. Por outro lado, o histograma das multíparas é disperso e apresenta uma maior freqüência entre os 42 e 63 dias. Este tipo de histograma para não produzir efeitos expressivos sobre a prenhez subseqüente necessita que as vacas tenham um reduzido intervalo parto primeiro-cio, alcançado por uma boa condição corporal ao parto ou ainda que o manejo alimentar pós-

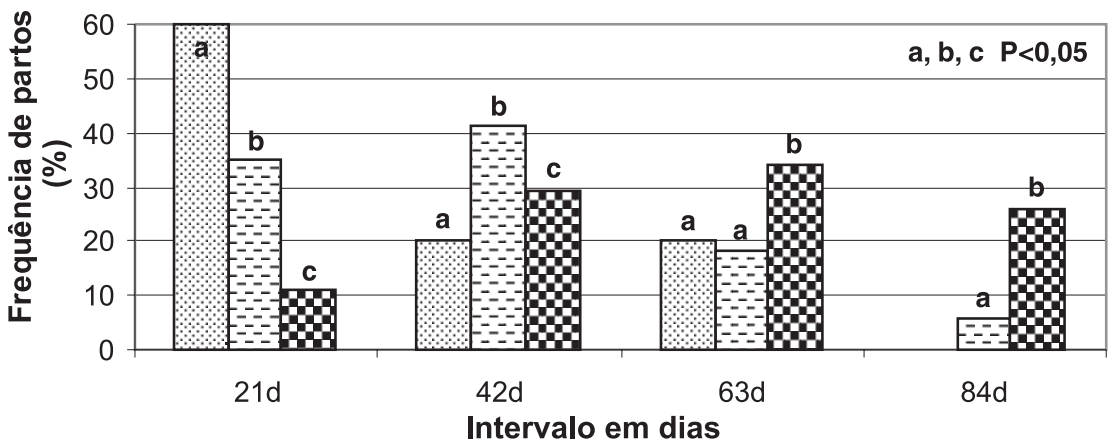

\section{Modelo Teórico Ideal}

G Vacas Primíparas

@ Vacas Multíparas

Figura 1. Comparação do histograma de parição médio durante 8 anos de vacas de corte primíparas e multíparas em relação ao modelo teórico ideal. 
parto garante ganhos de peso em torno de $0,500 \mathrm{Kg} / \mathrm{dia}$. Nas novilhas acasaladas aos 2 anos é normal a maior concentração de cios durante o início da estação de acasalamento. Pois é uma categoria que apresenta um peso mínimo de $300 \mathrm{~kg}$ e uma condição corporal em torno de 3,5-4,0. Esta concentração das concepções é expressa no HP do ano seguinte. Neste trabalho o histograma de parição das primíparas apresenta uma grande concentração de partos no início da estação de parição, mostrando que esta categoria concebeu no ano anterior de forma mais concentrada do que as multíparas. Situações como esta dificultam a realização de uma análise mais exata dos possíveis efeitos da data do parto sobre a prenhez no segundo acasalamento [1].

De um modo geral, as vacas primíparas apresentam um maior intervalo parto primeiro-cio do que multíparas devido ao fato de apresentarem um maior puerpério e ainda estarem em crescimento sendo: portanto mais sensíveis à restrição alimentar nessa fase do que as multíparas [4]. Isto evidencia a necessidade, nessa categoria, de ter um HP mais similar ao modelo teórico. Isto permite afirmar que histogramas de parição mais dispersos, devido a partos tardios são mais visíveis em multíparas do que primíparas.

A necessidade que os partos ocorram de forma concentrada no início da estação de parição é uma exigência dos sistemas de cria baseados em campo natural. Trabalhos conduzidos em um ambiente similar mostraram claramente o melhor desempenho reprodutivo de vacas cujos partos ocorreram no início do período de parição [6,8]. De uma maneira geral, vacas que parem ao início da estação de parição atingem maiores índices de repetição de prenhez $[2,4,10]$. A sub-época pode afetar a taxa de prenhez, sobretudo, quando há deficiência nutricional [1].

Os resultados nas multíparas evidenciaram que o histograma do ano de 1998 foi o que mais se afastou do modelo teórico, com menor frequiência de partos nos primeiros 21 dias $(\mathrm{P}<0,05)$ em relação aos demais e isto determinou menor taxa de prenhez 53,5\% (P<0,05). Contudo, no histograma de parição de 2003, ainda que tenha sido com uma frequiência similar ao de 1998 , foi observada uma maior taxa de prenhez $84,3 \%(\mathrm{P}<0,05)$. A taxa de prenhez do ano de 2003 se deve principalmente a ausência de seca $(969 \mathrm{~mm})$, concluindo que em anos bons o histograma de parição não possui grande efeito no desempenho reprodutivo subseqüente. Deste modo, o efeito de um histograma disperso em relação ao ideal pode ser neutralizado por meio de uma boa condição alimentar pós-parto. Entretanto, a tendência é que no ano seguinte os partos vão ocorrendo cada vez mais tarde e essas vacas venham a falhar. Por outro lado, é possível também que histogramas com alta freqüência de partos nos primeiros 42 dias também não assegurem altas taxas de prenhez, pois existem outros fatores como: as condições climáticas, condição corporal das vacas e a época de desmame que podem interferir, neutralizando o efeito do histograma no desempenho reprodutivo do rebanho.

Nos anos em que não há limitações climáticas, vacas que parem mais tardiamente conseguem diminuir o intervalo parto primeiro-cio, provavelmente, pelo fato de ter uma maior disponibilidade de alimento no pós-parto, entretanto, estas vacas podem apresentar um menor número de cios durante o período de monta e conseqüentemente uma menor probabilidade de conceber, resultando em menor prenhez [3,6].

Durante os anos em que ocorreram estiagens acentuadas 1998/99 e 2004/05, durante a estação de acasalamento (Tabela 3), as taxas de repetição de prenhez foram inferiores aos outros anos, tanto para primíparas $(64,5 \%, 64,7 \%)$ como para multíparas $(53,5 \%$, $67,5 \%)(\mathrm{P}<0,05)$. Esses resultados demonstraram uma interação entre o histograma de partos e a categoria da vaca. As primíparas na estação 1998/99 obtiveram uma taxa de prenhez de $64,5 \%(\mathrm{P}<0,05)$ superior as multíparas $(53,5 \%)$, mesmo sendo uma categoria mais sensível aos efeitos ambientais. Isto pode ser explicado pelo fato de que $77 \%$ dos partos ocorreram nos primeiros 42 dias nesta estação de parição. No mesmo período, nas multíparas, somente $31 \%$ dos partos ocorreram até os 42 dias da estação de parição, portanto inferior ao observado em primíparas. Desse modo, é estratégico buscar uma alta concentração de partos em primíparas, pois diante de efeitos climáticos adversos ainda poderá assegurar razoáveis índices reprodutivos.

Na Figura 2 o histograma das vacas primíparas está diferente do modelo teórico nos anos de maior (2000) e menor prenhez (1998), sugerindo que mesmo apresentando um histograma de parição diferente ao ideal as taxas de prenhez podem ser altas, porém desde que não haja interferências climáticas durante a estação de acasalamento. Também deve ser salientado que nesse caso cerca de $80 \%$ dos partos ocorreram nos primeiros 42 dias. Na Figura 3 pode-se verificar que o histograma de parição das vacas multíparas está mais afastado do modelo teórico tanto para maior prenhez como para menor prenhez, mesmo apresentando 9\% dos partos nos primeiros 21 dias este valor não inter- 


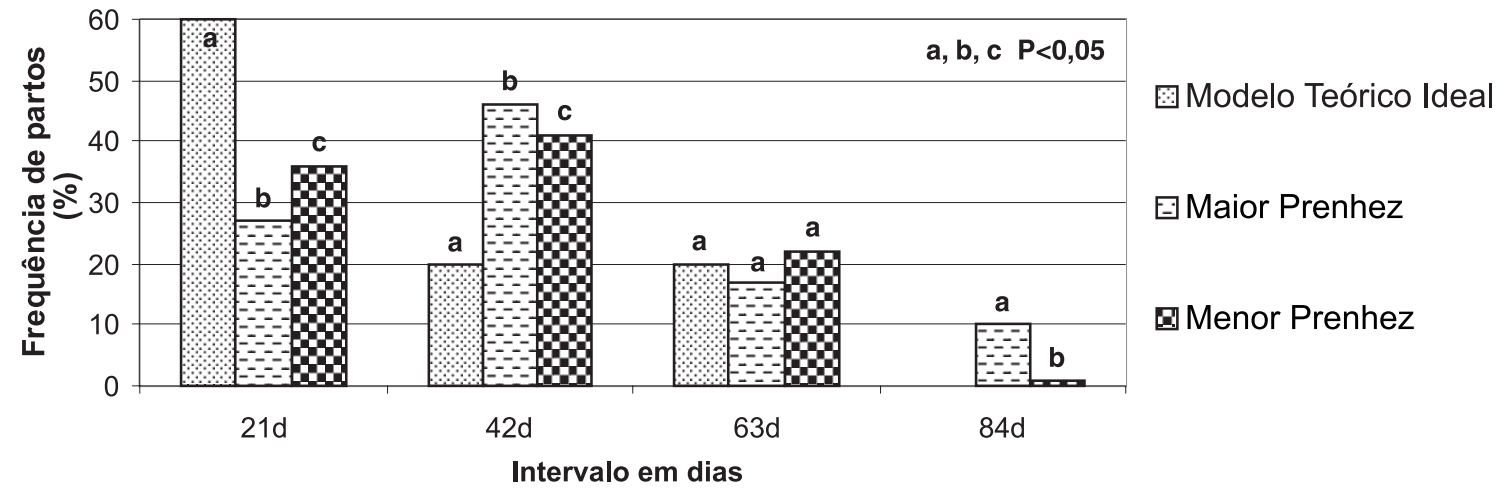

Figura 2. Comparação entre o histograma observado nos anos de maior $(96,5 \%)$ e menor taxa de prenhez $(64,5 \%)$ em vacas primíparas em relação ao modelo teórico ideal.

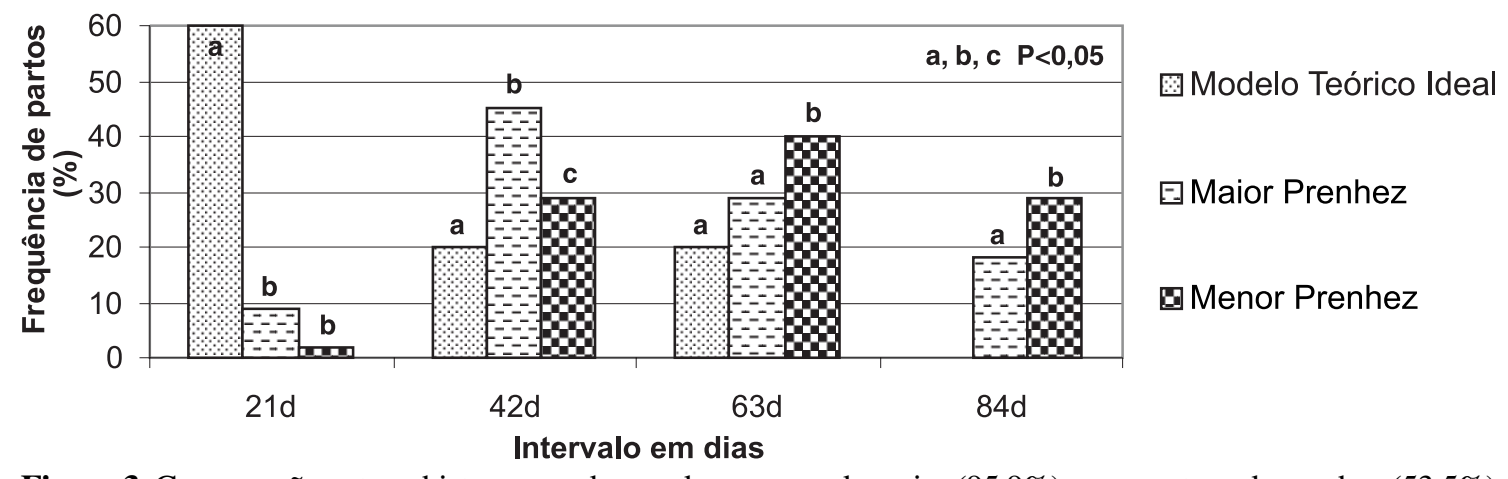

Figura 3. Comparação entre o histograma observado nos anos de maior $(95,9 \%)$ e menor taxa de prenhez $(53,5 \%)$ em vacas multíparas em relação ao modelo teórico ideal.

feriu negativamente na taxa de prenhez do ano subseqüente. Onde se conclui que mesmo o histograma sendo diferente do modelo teórico é possível obter altas taxas de prenhez, desde que não haja alterações climáticas como pode ser verificado no ano de 1998.

Portanto, cabe salientar que mesmo um rebanho apresentando um histograma de parição próximo ao ideal, ele por si só não garante uma alta taxa de prenhez, uma vez que podem existir diversos fatores durante o acasalamento que influenciam no desempenho reprodutivo da vaca.

\section{CONCLUSÕES}

Os histogramas de parição na criação comercial avaliada estão distantes do modelo ideal.

A ocorrência de limitações climáticas no acasalamento diminuiu a taxa de prenhez, contudo o efeito foi de menor magnitude quando o HP de parição foi mais concentrado nos primeiros 42 dias.

As vacas primíparas apresentaram histogramas com grande concentração de partos no início da estação. Deste modo foram menos sensíveis às adversidades climáticas do que as multíparas.

\section{REFERÊNCIAS}

1 Barcellos J.O.J. 1999. Manejo Integrado: um conceito para aumentar a produtividade dos sistemas de produção de bovinos de corte. In: Lobato J.F.P., Barcellos J.O.J, Kessler A.M. (Org.). Produção de bovinos de corte, 1.ed. Porto Alegre: pp.287-313.

2 Bourdon R. M. \& Brinks J. S. 1983. Calving date versus calving interval as a reproductive measure in beef cattle. Journal of Animal Science. 57: 1412-1417.

3 Dunn T.G., Ingalls J.E., Zimmerman D.R. \& Wiltbank J.N. 1969. Reproductive performance of 2-year-old Hereford and Angus heifers as influenced by pre and pos-calving energy intake. Journal of Animal Science. 29: 719-726.

4 Marshall D.M., Minqiang W. \& Freking B.A. 1990. Relative calving date of first-calf heifers as related to production efficiency and subsequent reproductive performance. Journal of Animal Science. 68: 1812-1817.

5 Nabinguer C., Sanguiné E., Netto M.A.G.C. 2005. Diagnóstico de sistemas de produção de bovinos de corte do Estado do rio Grande do Sul. 257p. 
6 Pimentel C.A. \& Pimentel M.A. 1983. Efeito do mês de parição sobre a função reprodutiva de vacas de corte. Revista Brasileira de Reprodução Animal. 7: 33-42.

7 Rovira J. 1996. Manejo nutritivo de los rodeios de cria em pastoreo. Montevideo. 287p.

8 Silva A.W.L. 1989. Taxas de reconcepção e intervalo parto-concepção influenciados pela sub-época e mês de parição de vacas de corte. Porto Alegre, RS. Dissertação (Mestrado em Agronomia) - Universidade Federal do Rio Grande do Sul.

9 SPSS. User's guide [computer program]. 2002. Statistics SPSS Inc Version 11.5 Headquarters. Chicago. IL, 1 CD.

10 Wittum T.E., Curtis C.R. \& Salman M.E. 1990. Management practices and their association with reproductive health and performance in Colorado beef herd. Journal of Animal Science. 68: 2642-2649. 